\title{
Disturbances and Biodiversity in the Fichtelgebirge
}

\author{
Anke Jentsch, Constanze Buhk, Carl Beierkuhnlein, Manuel Steinbauer \& Martin Alt
}

\begin{abstract}
Disturbance ecology, namely the interaction of natural and anthropogenic disturbance with distribution, composition and richness of biotic units is the focus of this vegetation survey. Data on presence-absence of plant species were recorded in 100 equidistant quadratic units of one hectare size covering an area of $4 \mathrm{x} 4 \mathrm{~km}^{2}$. Each unit is subdivided in relevés with a similar disturbance regime enabling a spatial quantification of different disturbance agents. Disturbance types are not only measured qualitatively but assessed quantitatively (frequency, seasonality, duration, size, form, distribution, selectivity). We conducted several equally designed studies in central Europe (Franconian Jura, Fichtelgebirge, Grafenwöhr, Elbe). Comparable data are also available for sites in Namibia, Morocco, Sweden, Ethiopia and Bangladesh. The Fichtelgebirge sample site is situated in north-eastern Bavaria (32U $709860 \mathrm{E} 5557570 \mathrm{~N})$, Germany. It is characterized by forest (44\%), agriculture (38\%), and grassland (22\%) and is located at about 600 $\mathrm{m}$ a.s.1.. The geology of the area consists of granite and phyllite bedrock; precipitation averages $650 \mathrm{~mm} / \mathrm{yr}$. The mean annual temperature since 1990 is $7.3^{\circ} \mathrm{C}$, (climate station Braunersgrün). Agriculture, hay and silage production, and forestry are the main forms of land use. The overall number of recorded plant species is 419. This report describes the available content in the vegetationplot database Disturbances and Biodiversity in the Fichtelgebirge (GIVD ID EU-DE-024).
\end{abstract}

Keywords: agriculture; cultural landscape; disturbance ecology; heterogeneity; pattern; plant diversity; vegetation.

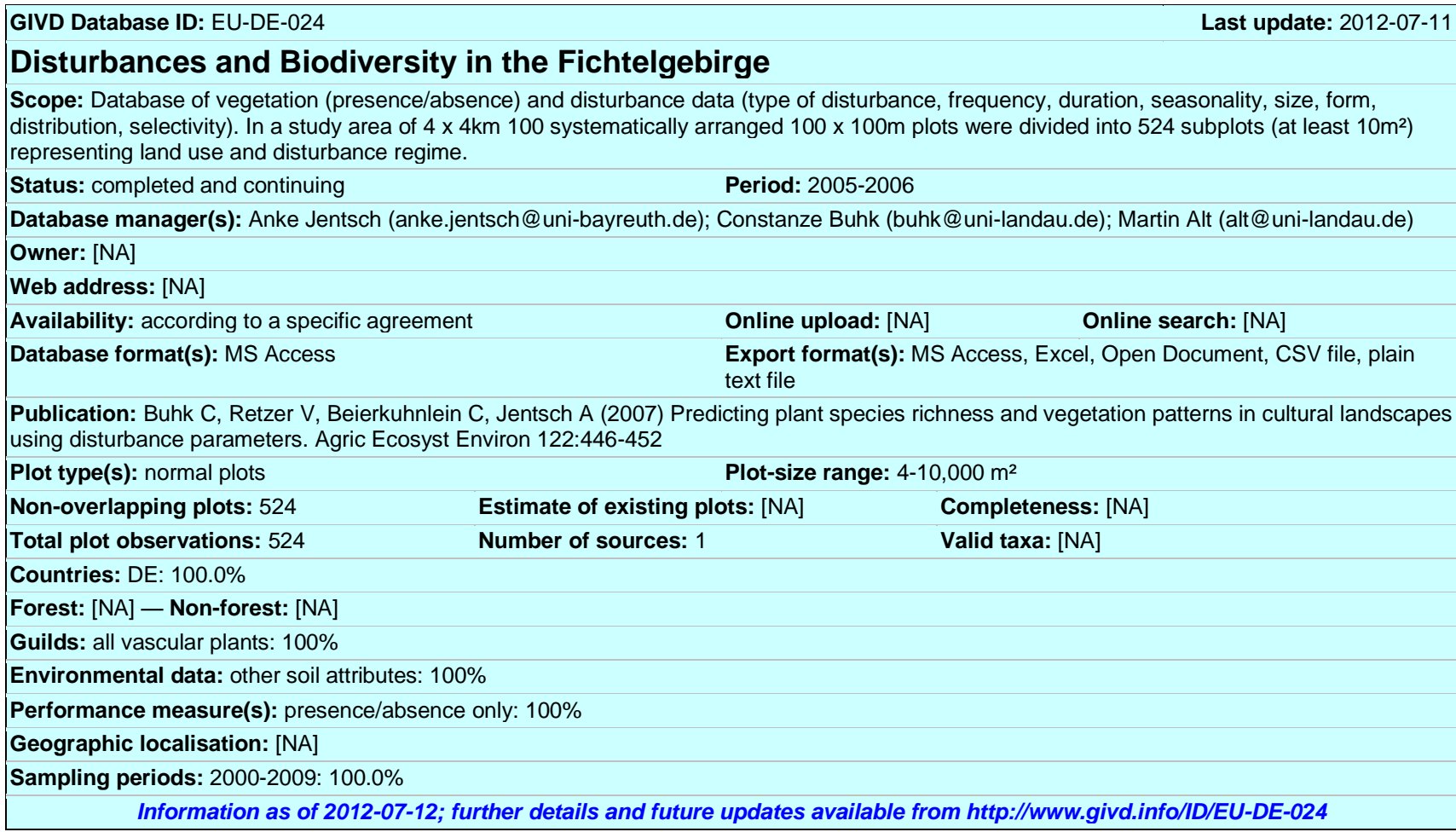

Anke Jentsch (anke.jentsch@uni-bayreuth.de), Carl Beierkuhnlein (carl.beierkuhnlein@uni-bayreuth.de), Manuel Steinbauer (manuel.steinbauer@uni-bayreuth.de)

BayCEER, Universität Bayreuth, Dr. Hans-Frisch-Str. 1-3, 95448 Bayreuth, GERMANY

Constanze Buhk (buhk@uni-landau.de), Martin Alt*(alt@uni-landau.de)

Institut für Umweltwissenschaften, Universität Koblenz - Landau, Fortstr. 7, 76829 Landau, GERMANY

*Corresponding author 